\title{
Examining child obesity risk level using fuzzy inference system
}

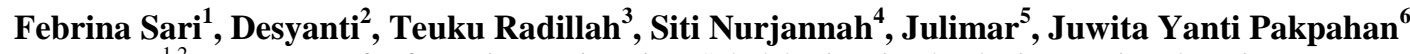 \\ ${ }^{1,2}$ Department of Informatics Engineering, Sekolah Tinggi Teknologi, Dumai, Indonesia \\ ${ }^{3}$ Department of Engineering, AMIK Mitra Gama, Duri, Indonesia \\ ${ }^{4,5,6}$ Nursing Study Program, Akademi Keperawatan Sri Bunga Tanjung, Dumai, Indonesia
}

\section{Article Info}

Article history:

Received Mar 7, 2021

Revised Jun 13, 2021

Accepted Jun 21, 2021

\section{Keywords:}

Body mass index

Depression

Fuzzy logic

Obesity

Sugeno method

\begin{abstract}
The doctor will determine the risk level of childhood obesity by using standard calculations, namely measuring the child's weight and height, and many other factors. Then the doctor will calculate the child's body mass index (BMI). The results of calculations made by the doctor will be compared with standard/normal values set by FAO/WHO, to obtain the level of risk of obesity in children. This study aims to analyze the risk level of obesity in children using the Sugeno method of Fuzzy Inference system, using the trapezoidal membership function and involving six input variables such as exercise habits, consumption of fast food, history of obesity of parents, and others. The application of the fuzzy inference system Sugeno method can help doctors to analyze the risk level of childhood obesity quickly and accurately with an accuracy rate of $85 \%$. The results of the implementation of the Sugeno method of Fuzzy Inference system showed that out of 140 children who were the object of the study, 119 children received a diagnosis of the level of risk of obesity which was the same as the diagnosis made by a doctor.
\end{abstract}

This is an open access article under the CC BY-SA license.

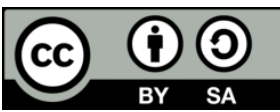

\section{Corresponding Author:}

Febrina Sari

Department of Informatics Engineering

Sekolah Tinggi Teknologi Dumai

Street Utama Karya Bukit Batrem II, South Dumai, Riau, Indonesia

Email: febri_ghaniya@yahoo.co.id

\section{INTRODUCTION}

Obesity is one of the problems in the world of health which is better known as obesity [1], [2] without realizing it, the risk of obesity in children is getting higher with the ease of getting fast food such as burgers, pizza, soft drinks and junk food that are available in food outlets [3], [4]. Obesity is a condition of excessive weakness in the body which is often expressed in terms of fat or overweight [2], [5] overweight reaches $20 \%$ of the standard bodyweight. Obesity also occurs as a result of an imbalance between the amount of incoming energy and that required by the body for various biological functions such as physical growth, development, and activity [6], [7].

Obesity in children can have an impact on the development of the child as a whole, the physical impact that can occur, such as type 2 diabetes mellitus [8], [9], high blood pressure, cholesterol in the blood which can form plaque in arteries [10] which can lead to heart attacks or strokes [11]. Meanwhile, the psychological impact, such as experiencing bullying or oppression and loss of self-esteem that causes feelings of hopelessness and results in depression. In addition, being overweight can also result in a decrease in the level of intelligence of children, this is because the activity and creativity of children are decreased and tend to be lazy. The doctor will determine the level of risk of obesity in children by measuring the child's weight and height, then the doctor will calculate the body mass index (BMI) [12]. These results will be 
compared with standard/normal values. BMI can be applied to a group of people to determine a trend, or it can be applied individually. When applied to individuals, only one of several assessments is used to determine the risk of weight-related disease [13].

Although the problem of obesity is important, unfortunately, there is no automatic system developed to help doctors determine the level of risk of obesity in children. The process of determining the risk of obesity in children has been done manually by doctors using direct methods or manual calculations based on standard guidelines, namely measuring the child's height and weight to obtain the BMI value with the formula $\mathrm{BMI}=$ body weight $(\mathrm{kg})$ divided by height $(\mathrm{m}) \mathrm{x}$ height $(\mathrm{m})$ then proceed by calculating the values for the other supporting variables, This, of course, will take a long time and even make mistakes in doing calculations. So this research needs to be done to make it easier for doctors to carry out the calculation process quickly and precisely, by applying the Sugeno fuzzy inference system method which can perform the calculation process automatically through the Matlab application.

The purpose of this study is how to see the success of the application of the Sugeno fuzzy inference system in determining the level of risk of obesity in children, as for reasons uses the Fuzzy Sugeno inference system because the technique can approach reasoning, especially in systems that deal with problems that are difficult to define using mathematical models. Fuzzy Sugeno has also been shown to provide excellent results when applied in various cases, for example a study conducted by [14] in evaluating kidney function, then a study conducted by [15] on diagnosing liver disorders, then [16] conducted a study on the diagnosis of hepatitis B. The fuzzy inference system has also been used by [17], [18] in his research to detect diabetes mellitus and diagnose colorectal cancer.

\section{RESEARCH METHOD}

\subsection{Research framework}

An explanation of each stage of the research that will be carried out from the beginning of the research to the end of the study will be described in the form of a research framework as shown in Figure 1.

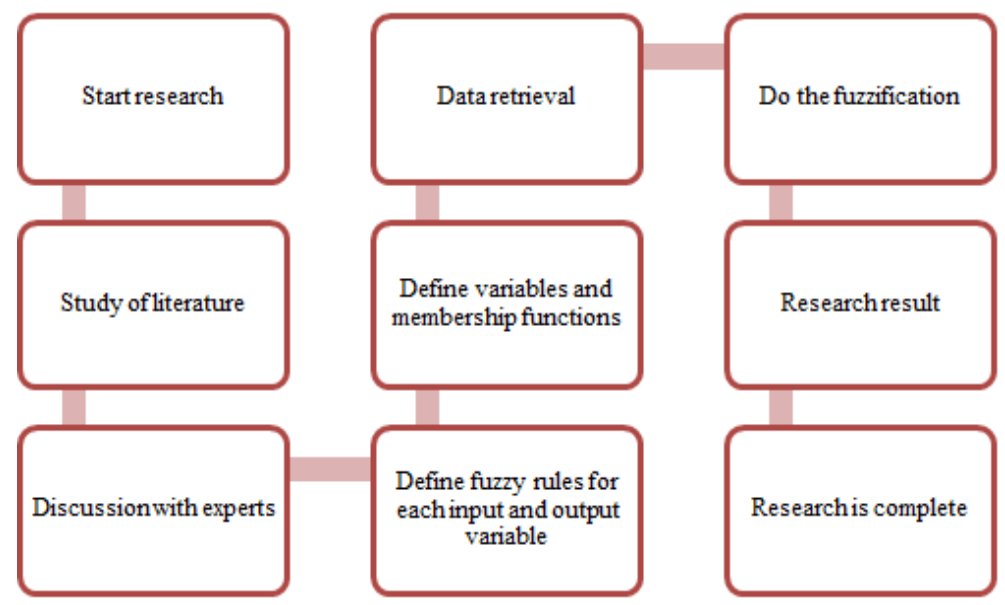

Figure 1. Research framework

\subsection{Method of collecting data}

Researchers obtained data for this study using of direct observation and interviews with experts, namely the pediatricians at the Dumai City Hospital. The results of this interview obtained the factors that are used as a basis for consideration to determine the level of risk of obesity in children, as well as how to do manual calculations using a child's body mass index (BMI) by doctors. These results will be compared with the standard/normal values set by FAO/WHO. The data for this study are primary, obtained directly from pediatricians in the form of Ms. Excel. The sample data used in this study were 140 children who had consulted with a pediatrician at the Dumai City Hospital and had received a diagnosis of the level of risk of obesity.

\subsection{Research tools}

The implementation of the Sugeno method of fuzzy inference system will involve six input variables which are antecedents and one output variable which is a consequence. The variables involved in this study refer to the results of consultations with pediatricians and refer to research conducted by [10], [19]-[20], the 
membership function that will be used in this study is an up and down linear membership function for gender variables and a history of parental obesity [21]-[22]. While the trapezium membership function is used for BMI variables, exercise habits, fiber consumption, and fast food. The variables and membership functions used in this study can be seen in Table 1 .

Table 1. Variables and fuzzy sets

\begin{tabular}{cccc}
\hline Function & Variable & Category & Domain \\
\hline \multirow{4}{*}{ GMI } & Thin & {$[0-15]$} \\
& Normal & {$[12-26]$} \\
& Fat & {$[22-26]$} \\
& Parental history of obesity & Male & {$[0-100]$} \\
& & Female & {$[50-100]$} \\
& & There is no & {$[0-100]$} \\
Input & Sports habit & Often & {$[50-100]$} \\
& & Rarely & {$[0-40]$} \\
& & Never & {$[10-100]$} \\
& Consumption of fiber & Lots & {$[0-100]$} \\
& & A little & {$[10-100]$} \\
& Consumption & There is no & {$[70-100]$} \\
& Fast food & Never & {$[0-40]$} \\
& Rarely & {$[10-100]$} \\
& & Often & {$[70-100]$} \\
& Obesity risk level & Low & {$[0-40]$} \\
& & Medium & {$[10-100]$} \\
& & High & {$[70-100]$} \\
\hline \multirow{2}{*}{ Output } & &
\end{tabular}

\subsection{Fuzzy logic}

This study used the Sugeno method of fuzzy logic [23]-[25], or better known as the Sugeno model fuzzy inference systems and abbreviated as Takagi-Sugeno-Kang Models (TSK) Models [26], [27]. Fuzzy inference systems (FIS), often referred to as fuzzy inference engines, are systems that are capable of reasoning with principles similar to human reasoning, namely reasoning with instincts. Fuzzy is based on three components, namely basic command, database and, reasoning mechanisms. The basic rule consists of antecedent and consequent [28], with the rule If $\mathrm{A}$ is antecedent then $\mathrm{B}$ is Consequent. Before the existence of fuzzy logic theory, the system had strict logic in the form of true and false values. After the existence of the fuzzy theory, a fuzziness value appears, which is a value that is between right and wrong, fuzzy has the advantage of solving problems that contain uncertainty and partial truth [29]. This means that a situation can have two values at the same time, but the value depends on the membership weight it has. Fuzzy logic has a set that can be represented in the form of a membership function.

The membership function is a curve that shows the mapping of input data points into a value called the degree of membership, where the value is between 0 and 1 . This membership value is the result of the operation of two sets, also known as $\alpha$-predicate. This two-set operation process will use three basic operators according to [14], [30], [31]:

- $\quad$ AND operator, with the form $\mu \mathrm{A} \cap \mathrm{B}=\operatorname{Min}(\mu \mathrm{A}[\mathrm{X}], \mu \mathrm{B}[\mathrm{Y}])$.

- $\quad$ OR operator, with the form $\mu \mathrm{AUUB}=\operatorname{Max}(\mu \mathrm{A}[\mathrm{X}], \mu \mathrm{B}[\mathrm{Y}])$.

- $\quad$ NOT operator, with the form $\mu \mathrm{A}^{\prime}=1-\mu \mathrm{A}[\mathrm{X}]$.

\section{RESULTS AND DISCUSSION}

\subsection{Variable defining stages}

Sugeno fuzzy inference system will provide results or output after doing the variable definition stage. Research in determining the level of risk of obesity in children, researchers used six input variables, namely:

- Input variable with trapezoid curve [32], [33] also uses trapezoidal curves in his research.

Body mass index (BMI) is a measure used to assess the proportionality of the ratio between a person's height and weight, to find out the BMI value, it can be calculated using the following formula:

BMI $=($ Weight $(\mathrm{Kg})) /($ Height $(\mathrm{m}) *$ Height $(\mathrm{m}))$

The BMI variables, habits sport, fiber consumption, and fast food consumption consist of three sets. Using fluctuating curves. Figure 2 (a)-(d) is a representation of each of the membership functions of each variable sequentially. The BMI membership function is represented using a trapezoidal curve. 


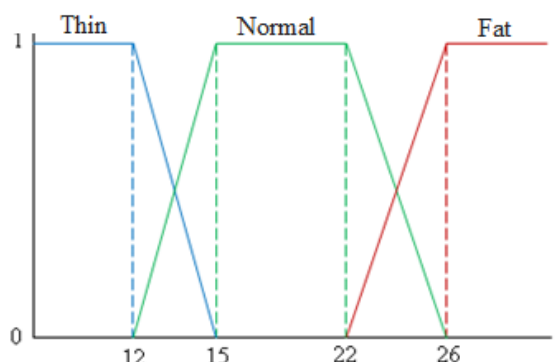

(a)

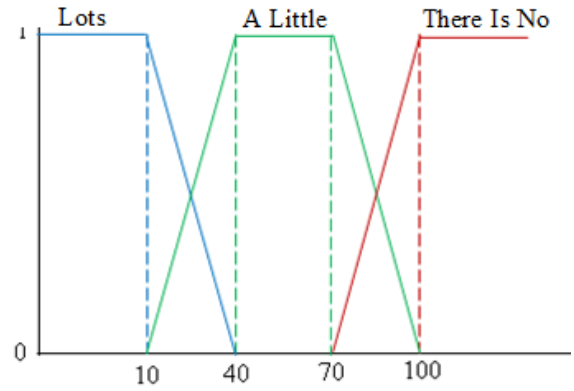

(c)

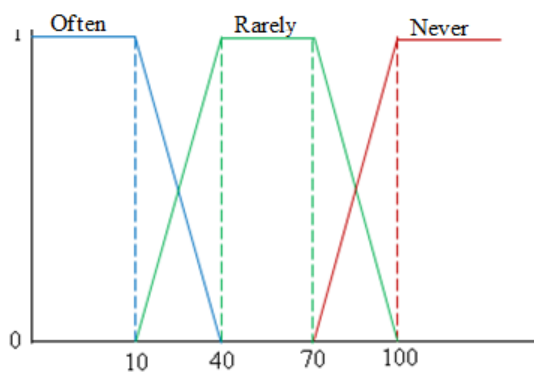

(b)

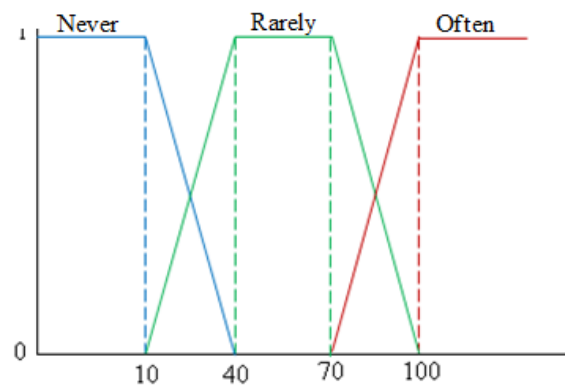

(d)

Figure 2. Representation of the trapezoidal curve membership function, (a) Variable BMI, (b) Variable sports habit, (c) Variable consumption of fiber, and (d) Variable consumption fast food

- Input variable, with an up and down curve

Variable gender and parental history of obesity uses a descending and ascending curve consisting of two fuzzy sets, Figure 3 (a) is a membership representation of the gender variable and Figure 3 (b) is a membership representative of the history of parental obesity.

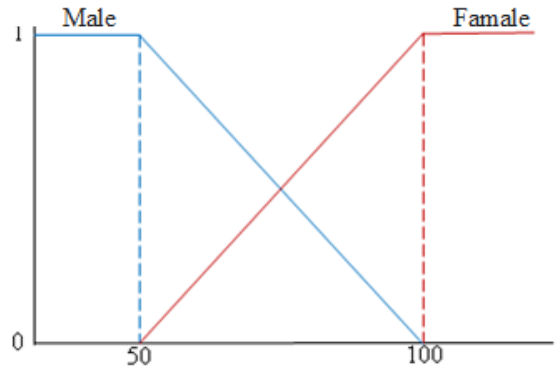

(a)

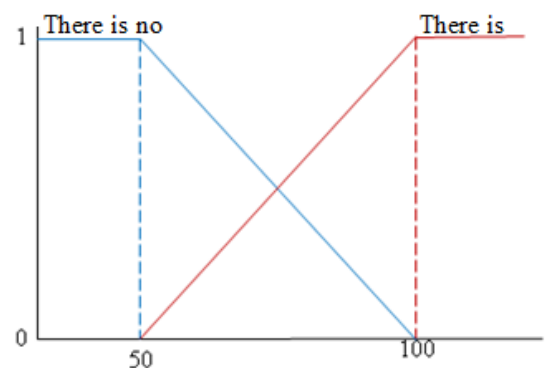

(b)

Figure 3. Representation of an up and down curve membership function, (a) Variable gender and (b) Variable parental history of obesity

\subsection{Stage determining rule (inference)}

Rule formation is the process of defining the relationship between each membership function used [34]-[35], based on the unit of reasoning in fuzzy inference in the form if $x$ is A and $y$ is B then $z$ is C. At this stage, the researcher combines the fuzzy sets skinny, normal, fat, male, female, not available, available, often, rarely, never, many, little, none, low, medium, high, of the seven variables, 256 rules are obtained.

\subsection{Manual calculation stages}

The following is data from the sample of the first child used in the study, namely as follows: name: 1st patient, gender: female, weight: $21 \mathrm{~kg}$, height: $127 \mathrm{~cm}$, parental history of obesity: there is no sports habit: rarely, fiber consumption: a little, consumption of fast food: rarely 
The BMI value for Patient 1 is

BMI variable membership degree 13.0200260401. Then the membership value of the fuzzy BMI set with membership degrees of 13.0200260401 can be found by:

$\mu_{B M I}$ Thin [13.0200260401] $=0.659991319967$

$\mu_{B M I}$ Normal $[13.0200260401]=0.340008680033$

$\mu_{B M I}$ Fat $[13.0200260401]=0$

Degree of membership of the female gender variable is (100). Then the membership value of the gender fuzzy set is:

$\mu_{-}\left(\operatorname{sex} \_\right.$sex $)$male $[100]=0$

$\mu_{-}\left(\operatorname{sex} \_\right.$sex $)$female $[100]=1$

Degree of membership of the rare sports habit variable is (55). Then the membership value of the fuzzy sports habits obtained are:

$\mu \quad$ (sports_ habit) often $[55]=0$

$\mu_{-}$(sports_ habit) rarely $[55]=1$

$\mu_{-}$(sports_ habit) never [55] $=0$

The values are in the set of low and moderate risk levels of obesity that are between the domains [10] and then the results are obtained

$$
\begin{aligned}
& \mu_{\text {Risk }} \text { Obesity } \\
& L o w[23.4641666521]=\frac{40-23.4641666521}{40-10}=0.551194444929 \\
& \mu_{\text {Risk_Obesity }} \text { Medium }[23.4641666521]=\frac{23.4641666521-10}{40-10}=0.448805555071 \\
& \mu_{\text {Risk_Obesity }} \text { high }[23.4641666521]=0
\end{aligned}
$$

The results of the analysis of the level of risk of childhood obesity on behalf of patient one can be seen in Figure 4. From the picture, it can be seen that the level of risk for children is at a low level.

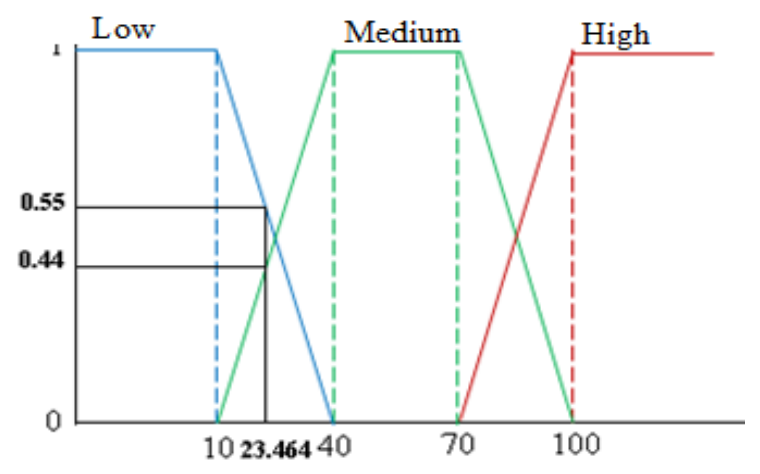

Figure 4. Membership value of patient's 1st obesity risk level

\subsection{Fuzzy Sugeno implementation}

After the data has been prepared, the next step is to carry out the testing process using the Matlab application in the form of transforming observational data into variables, transforming observational data into seven variables. Inputting fuzzy sets into the application is based on Table 1. Figure 5 (a) is a display of fuzzy sets for BMI variables for sports habits, fiber consumption, and fast food consumption which consists of 3 sets using trapezoidal curves, while for fuzzy sets for type variables gender and history of obesity of the parents consisted of two sets using linear ascending and descending curves, can be seen in Figure 5 (b), while Figure 5 (c) is a fuzzy set view for the output variable which consists of three sets. 
Membership Function Editor: Untitled2 - $\square \times$

File Edit View
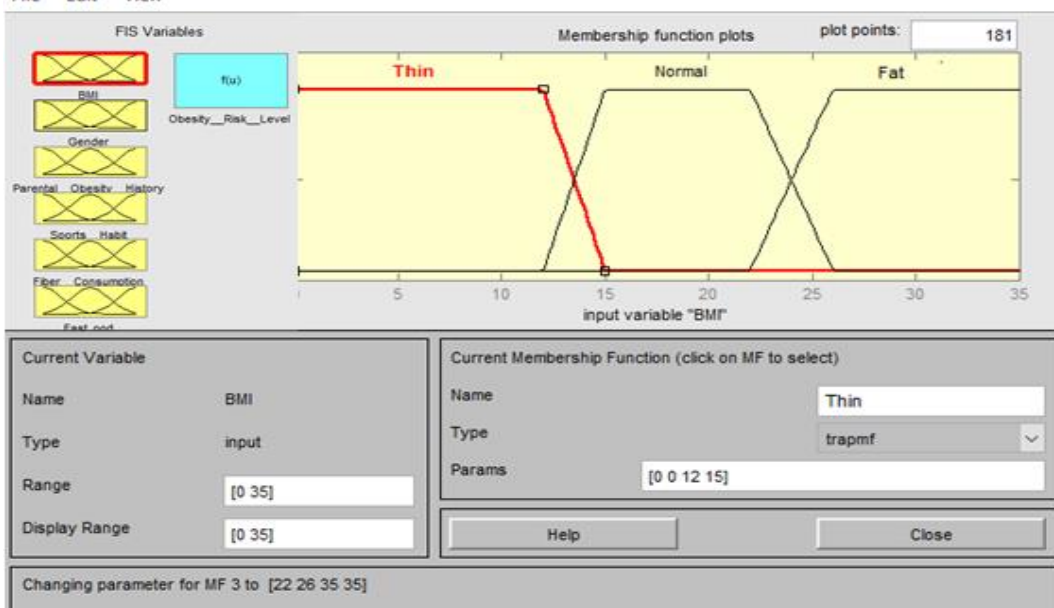

(a)

Dembership Function Editor: matlap inggris

File Edit View
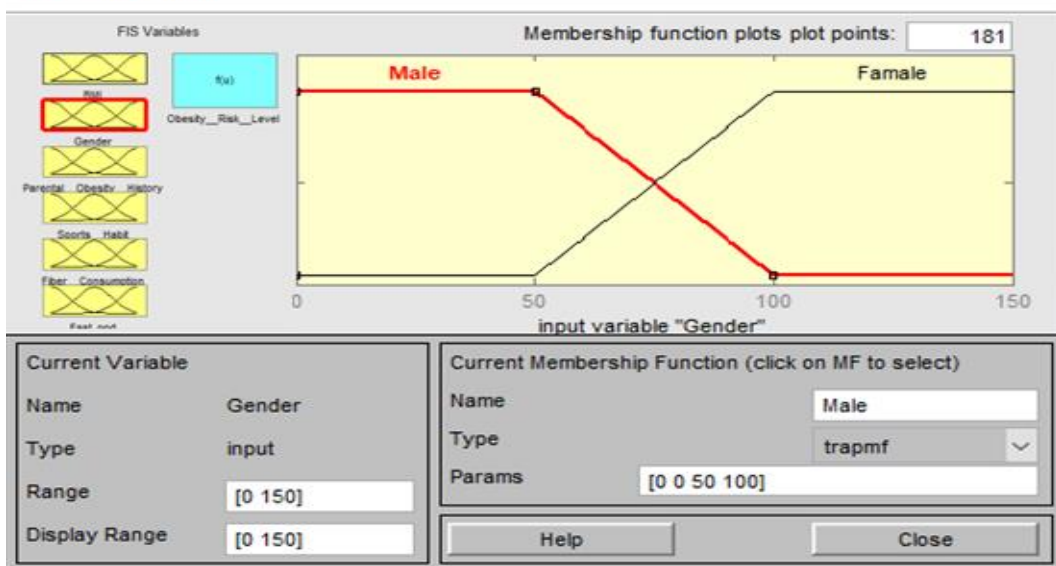

Changing parameter for MF 2 to $\left[\begin{array}{lll}50 & 100 & 156 \\ 204\end{array}\right]$

(b)

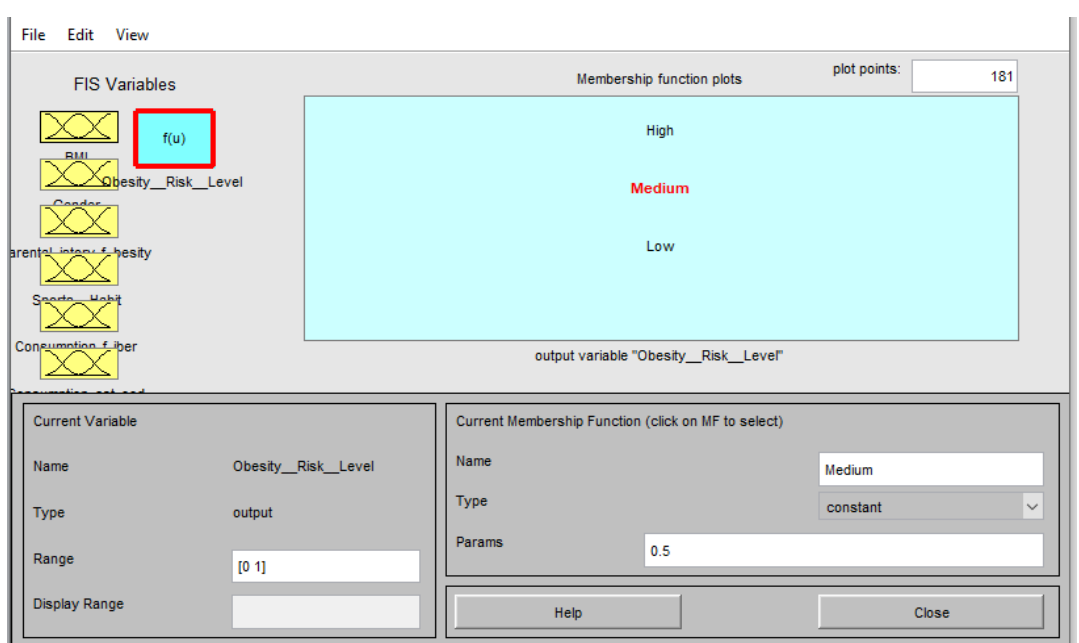

(c)

Figure 5. Display of the fuzzy set input and output, (a). Input variable with trapezoid curve, (b). Input variable with an up and down linear curve, and (c). Fuzzy set for output variables 


\subsection{Rule establishment and defuzzification}

The formation of basic rules for fuzzy data is done by defining the relationship between the membership function and the form of the membership function that will be generated [36], it can be seen in Figure 6 (a) then the defuzzification stage, defuzzification is the final stage of a series of fuzzy processes, the results of testing using the Average value method the level of risk of obesity in the 1st (first) child with the input value as previously described, shows that the results of the Sugeno fuzzy application are the same as the results of the doctor's analysis. Figure 6 (b) is the result of using the Fuzzy Matlab Toolbox application. The Figure 6 (a), (b) shows the same input and output values between manual calculations and calculations using Matlab.

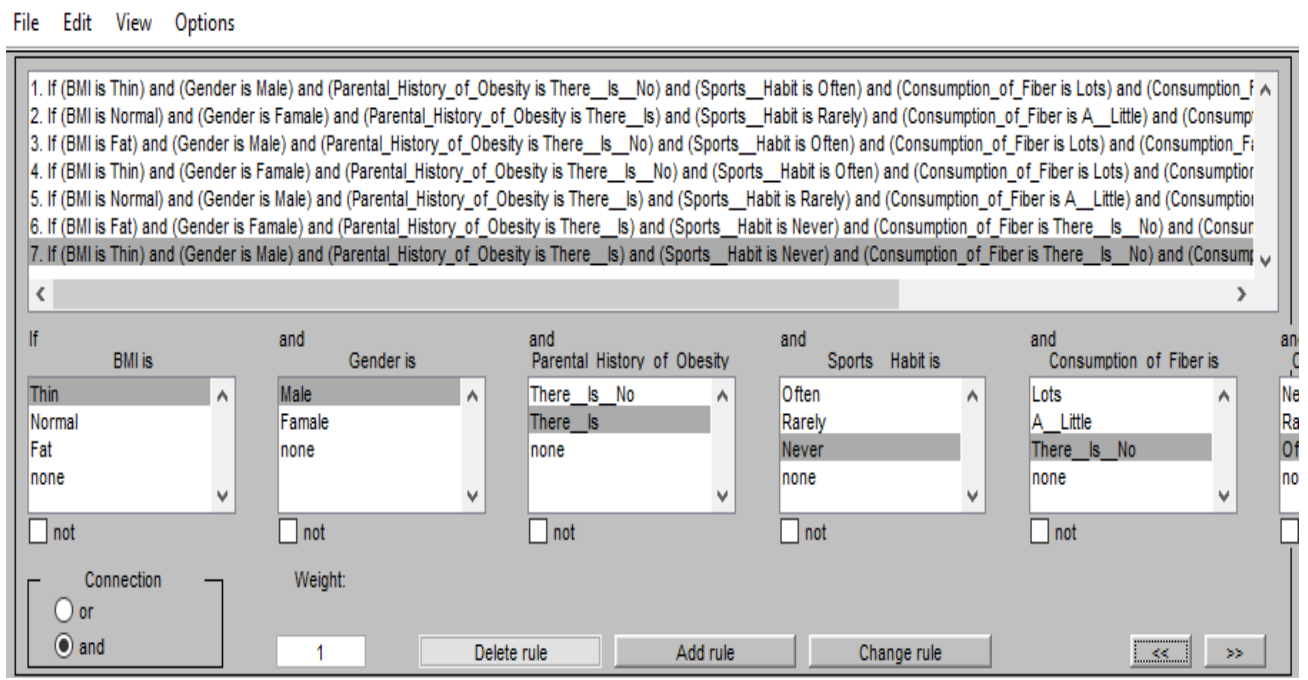

(a)

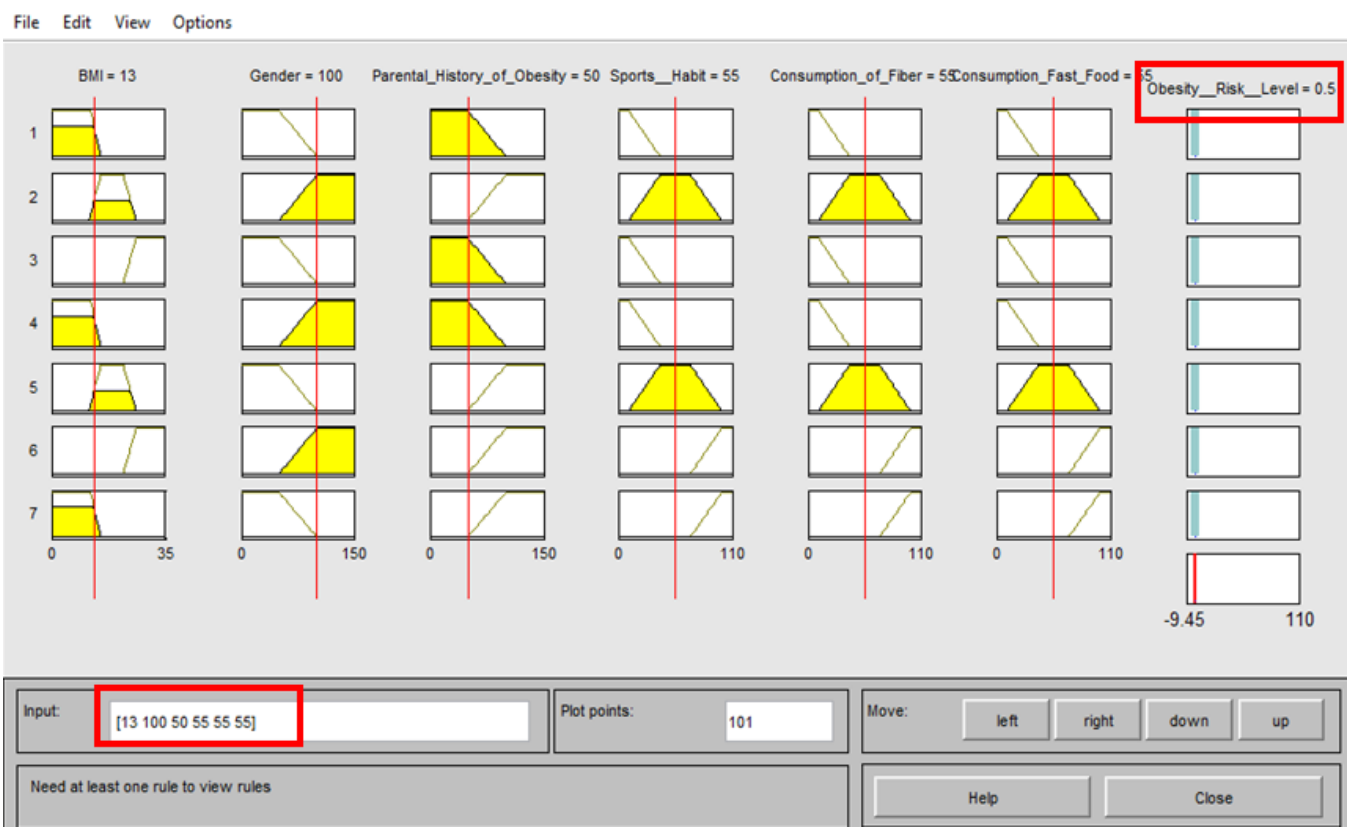

(b)

Figure 6. Rule establishment and defuzzification, (a) Rule establishment and (b) Result of using the fuzzy

\subsection{Test results}

Testing is done by comparing the results of calculations from the Matlab application using Sugeno's fuzzy inference system model with the doctor's diagnosis. Figure 7 shows that the results of the doctor's diagnosis are not much different from the results issued by the Matlab application with the calculation of the Sugeno fuzzy inference system model. 


\section{Diagnostic Result Comparison Graph Child Obesity Risk Level}
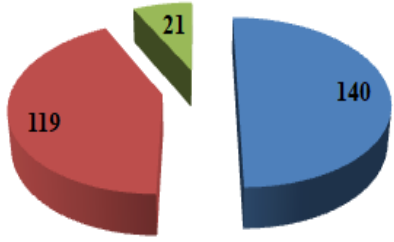

Doctor's Dingnosis Results

- Fuzzy Analysis Results

= Invalid Diagnostic Result

Figure 7. The results of comparison of diagnosis

Based on Figure 7, the level of accuracy in the application of the Sugeno fuzzy inference system can be found, with the results:

$=($ number of accurate data / total samples $) * 100 \%$

$=(119 / 140) * 100 \%=87.5 \%$

The test results show that the application of fuzzy logic to determine the level of risk of obesity in children can run well.

\section{CONCLUSION}

The results showed that the application of the Fuzzy Sugeno Inference System can make it easier for doctors to carry out the calculation process and obtain the analysis of the risk level of childhood obesity more quickly and accurately because doctors simply input the value of the six variables which are determinants of the risk level of obesity in children, while the variables used are BMI, gender, parental history of obesity, sports habit, consumption of fiber, consumption, fast food. The value of the six variables will be entered into the Input column, then Matlab will process the values of the six input variables, then Matlab will automatically issue the results of the risk level for child obesity. The assessment of the risk level of obesity is carried out specifically for elementary school children aged 7-12 years.

The Matlab application can be used to analyze the level of risk of obesity in children; this is evidenced by the results of the calculation of the validity level showing the number $87.5 \%$. Where 119 children have the same risk level of obesity as the results of manual doctor analysis, to be able to use the Fuzzy Sugeno Inference System, doctors need to be given training.

\section{REFERENCES}

[1] S. Negash, C. Agyemang, T. E. Matsha, N. Peer, R. T. Erasmus, and A. P. Kengne, "Differential prevalence and associations of overweight and obesity by gender and population group among school learners in South Africa: A cross-sectional study," BMC Obes., vol. 4, no. 1, pp. 1-8, 2017, doi: 10.1186/s40608-017-0165-1.

[2] T. Adom, A. De Villiers, T. Puoane, and A. P. Kengne, "Prevalence and correlates of overweight and obesity among school children in an urban district in Ghana," BMC Obes., vol. 6, no. 1, pp. 1-11, 2019, doi: 10.1186/s40608-019-0234-8

[3] H. Abiola Afolabi et al., "The relationship between obesity and other medical comorbidities," Malawi Med. J., vol. 31, no. 1, pp. 19-24, 2019, doi: DOI: 10.4314/mmj.v31i1.4.

[4] R. K. H. Hafizurrachman, "Junk Food Consumption and Symptom of Mental Health Problems; A Meta-Analysis," Kesmas J. Kesehat. Masy. Nas. (National Public Heal. Journal), vol. 16, no. 1, pp. 1-8, 2021, doi: 10.21109/kesmas.v16i1.4541.

[5] M. De Onis, M. Blössner, and E. Borghi, "Global prevalence and trends of overweight and obesity among preschool children," Am. J. Clin. Nutr., vol. 92, no. 5, pp. 1257-1264, 2010, doi: 10.3945/ajen.2010.29786.

[6] N. H. Tate, H. E. Dillaway, H. N. Yarandi, L. M. Jones, and F. L. Wilson, "An examination of eating behaviors, physical activity, and obesity in African American adolescents: Gender, socioeconomic status, and residential status differences," J. Pediatr. Heal. Care, vol. 29, no. 3, pp. 243-254, 2015, doi: 10.1016/j.pedhc.2014.11.005.

[7] L. Srinag, K. N. Maruthy, S. K. Kareem, A. V. Siva Kumar, K. Kumar, and J. Preetham Gurja, "Impact of overweight on cognition and psychomotor skills among children with overweight," Obes. Med., vol. 18, no. February, - 2020, doi: 10.1016/j.obmed.2020.100191.

[8] B. N. Conway et al., "The obesity epidemic and rising diabetes incidence in a low-income racially diverse southern US cohort," PLoS One, vol. 13, no. 1, pp. 1-18, 2018, doi: 10.1371/journal.pone.0190993.

[9] P. M. Krueger and E. N. Reither, "Mind the Gap: Race/Ethnic and Socioeconomic Disparities in Obesity," Curr. Diab. Rep., vol. 15, no. 11, pp. 1-9, 2015, doi: 10.1007/s11892-015-0666-6.

[10] G. I. Wanghi, L. Lytle, Z. P. Kabututu, A. R. Buhendwa, and K. E. Sumaili, "Prevalence and determinants of overweight and obesity among school-aged children and adolescents," International Journal Public Health Science, 
vol. 9, no. 4, pp. 379-386, 2020, doi: 10.11591/ijphs.v9i4.20445.

[11] W. O. Adebimpe, "Prevalence and knowledge of risk factors of childhood obesity among school-going children in Osogbo, south-western Nigeria," Malawi Med. J., vol. 31, no. 1, pp. 19-24, 2019, doi: 10.4314/mmj.v31i1.4.

[12] N. C. Buhendwa RA, Roelants M, Thomis M, "Nutritional status and height, weight and BMI centiles of school-aged children and adolescents of 6-18- years from Kinshasa (DRC)," Ann Hum Bio, vol. 44, no. 6, pp. 554-561, 2017.

[13] K. H. Larwin and S. H. Woods, "The obesity gap: An investigation using the behavioral risk factor surveillance system data for ohio," International Journal Public Health Science, vol. 10, no. 1, pp. 169-174, 2021, doi: 10.11591/ijphs.v10i1.20569.

[14] G. Improta, V. Mazzella, D. Vecchione, and and M. T. S. Santini, "Fuzzy logic-based clinical decision support system for the evaluation of renal function in posttransplant patients," J. Eval. Clin. Pract., vol. 26, no. 4, pp. 12241234, 2019, doi: 10.1111/jep.13302.

[15] A. A. E. badie A. Allah Kamel and F. A. E. S. Z. El-Mougi, "A Fuzzy Decision Support System for Diagnosis of Some Liver Diseases in Educational Medical Institutions," Int. J. Fuzzy Log. Intell. Syst., vol. 20, no. 4, pp. 358368, 2020, doi: 10.5391/IJFIS.2020.20.4.358.

[16] G. Ahmad, M. A. Khan, S. Abbas, A. Athar, B. S. Khan, and M. S. Aslam, "Automated Diagnosis of Hepatitis B Using Multilayer Mamdani Fuzzy Inference System,” J. Healthc. Eng., vol. 2019, no. i, 2019.

[17] M. Benamina, B. Atmani, and S. Benbelkacem, "Diabetes Diagnosis by Case-Based Reasoning and Fuzzy Logic," Int. J. Interact. Multimed. Artif. Intell., vol. 5, no. 3, 72-80, 2018, doi: 10.9781/ijimai.2018.02.001.

[18] T. T. Ngan, L. T. H. Lan, T. M. Tuan, L. H. Son, L. M. Tuan, and N. H. Minh, "Colorectal Cancer Diagnosis with Complex Fuzzy Inference System,” Adv. Intell. Syst. Comput., vol. 1013, pp. 11-20, 2020.

[19] H. Ene-Obong, V. Ibeanu, N. Onuoha, and A. Ejekwu, "Prevalence of overweight, obesity, and thinness among urban school-aged children and adolescents in southern Nigeria," Food Nutr. Bull., vol. 33, no. 4, pp. 242-250, 2012, doi: 10.1177/156482651203300404.

[20] T. C. E. Mosha and S. Fungo, "Prevalence of overweight and obesity among children aged 6-12 years in Dodoma and Kinondoni municipalities, Tanzania," Tanzan. J. Health Res., vol. 12, no. 1, pp. 6-16, 2010.

[21] G. Kambondo and B. Sartorius, "Risk factors for obesity and overfat among primary school children in Mashonaland west province, Zimbabwe," Int. J. Environ. Res. Public Health, vol. 15, no. 2, 2018, doi: 10.3390/ijerph15020249.

[22] M. Cossio-Bolaños, M. de Arruda, C. L. Andruske, C. Luarte-Rocha, and R. Gómez-Campos, "Secular trends of physical growth and abdominal adiposity of school children and adolescents living at a moderate altitude in Peru," Am. J. Phys. Anthropol., vol. 162, no. 2, pp. 385-392, 2017, doi: 10.1002/ajpa.23121.

[23] O. Lamrabet, A. Ech-Charqy, E. H. Tissir, and F. El Haoussi, "Sampled data Control for Takagi-Sugeno Fuzzy Systems with Actuator Saturation," Procedia Comput. Sci., vol. 148, no. Icds 2018, pp. 448-454, 2019.

[24] Z. Civelek, "Optimization of fuzzy logic (Takagi-Sugeno) blade pitch angle controller in wind turbines by genetic algorithm," Eng. Sci. Technol. an Int. J., vol. 23, no. 1, pp. 1-9, 2020, doi: 10.1016/j.jestch.2019.04.010.

[25] A. Pamuji, "Fuzzy Logic Inference System for Determining The Quality Assesment of Students Learning ICT," Sci. J. Informatics, vol. 4, no. 1, pp. 57-65, 2017, doi: 10.15294/sji.v4i1.7082.

[26] P. Hajek and V. Olej, "Defuzzification Methods in Intuitionistic Fuzzy Inference Systems of Takagi-Sugeno type: The Case of Corporate Bankruptcy Prediction," 2014 11th Int. Conf. Fuzzy Syst. Knowl. Discov. FSKD 2014, pp. 232-236, 2014, doi: 10.1109/FSKD.2014.6980838.

[27] Y. Liu and F. Liu, "An Adaptive Neuro-Complex-Fuzzy-Inferential Modeling Mechanism for Generating HigherOrder TSK Models," Neurocomputing, vol. 365, pp. 94-101, 2019, doi: 10.1016/j.neucom.2019.07.042.

[28] M. Blej and M. Azizi, "Comparison of Mamdani-type and Sugeno-type fuzzy inference systems for fuzzy real time scheduling,” Int. J. Appl. Eng. Res., vol. 11, no. 22, pp. 11071-11075, 2016.

[29] N. Wulandari and A. G. Abdullah, "Design and Simulation of Washing Machine using Fuzzy Logic Controller (FLC)," IOP Conf. Ser. Mater. Sci. Eng., 2018, vol. 384, no. 1, doi: 10.1088/1757-899X/384/1/012044.

[30] L. T. Hong Lan et al., "A New Complex Fuzzy Inference System With Fuzzy Knowledge Graph and Extensions in Decision Making," IEEE Access, vol. 8, pp. 164899-164921, 2020, doi: 10.1109/access.2020.3021097.

[31] A. Bakhshipour, H. Zareiforoush, and I. Bagheri, "Application of Decision Trees and Fuzzy Inference System for Quality Classification and Modeling of Black and Green Tea Based on Visual Features," J. Food Meas. Charact., vol. 14, no. 3, pp. 1402-1416, 2020, doi: 10.1007/s11694-020-00390-8.

[32] G. Improta, V. Mazzella, D. Vecchione, S. Santini, and M. Triassi, "Fuzzy logic-based clinical decision support system for the evaluation of renal function in post-Transplant Patients," J. Eval. Clin. Pract., vol. 26, no. 4, pp. 1224-1234, 2020, doi: 10.1111/jep.13302.

[33] A. S. De Oliveira Goes and R. C. L. De Oliveira, "A Process for Human Resource Performance Evaluation Using Computational Intelligence: An Approach Using a Combination of Rule-Based Classifiers and Supervised Learning Algorithms," IEEE Access, vol. 8, pp. 39403-39419, 2020, doi: 10.1109/ACCESS.2020.2975485.

[34] C. Ylenia et al., "A Clinical Decision Support System based on fuzzy rules and classification algorithms for monitoring the physiological parameters of type-2 diabetic patients," Math. Biosci. Eng., vol. 18, no. 3, pp. 26532674, 2021, doi: $10.3934 / \mathrm{mbe} .2021135$.

[35] F. Cavallaro, "A Takagi-Sugeno fuzzy inference system for developing a sustainability index of biomass," Sustain., vol. 7, no. 9, pp. 12359-12371, 2015, doi: 10.3390/su70912359.

[36] H. H. Azwir and B. A. Kalinggo, "Multistage Fuzzy Inference System for Solving Problems in Performance Appraisal," ICSECC 2019 - Int. Conf. Sustain. Eng. Creat. Comput. New Idea, New Innov. Proc., 2019, pp. 200205, doi: 10.1109/ICSECC.2019.8907212. 